Seifert, Bernd-Ulrich; Vilser, Walthard:

Retinal vessel analyzer (RVA) - design and function

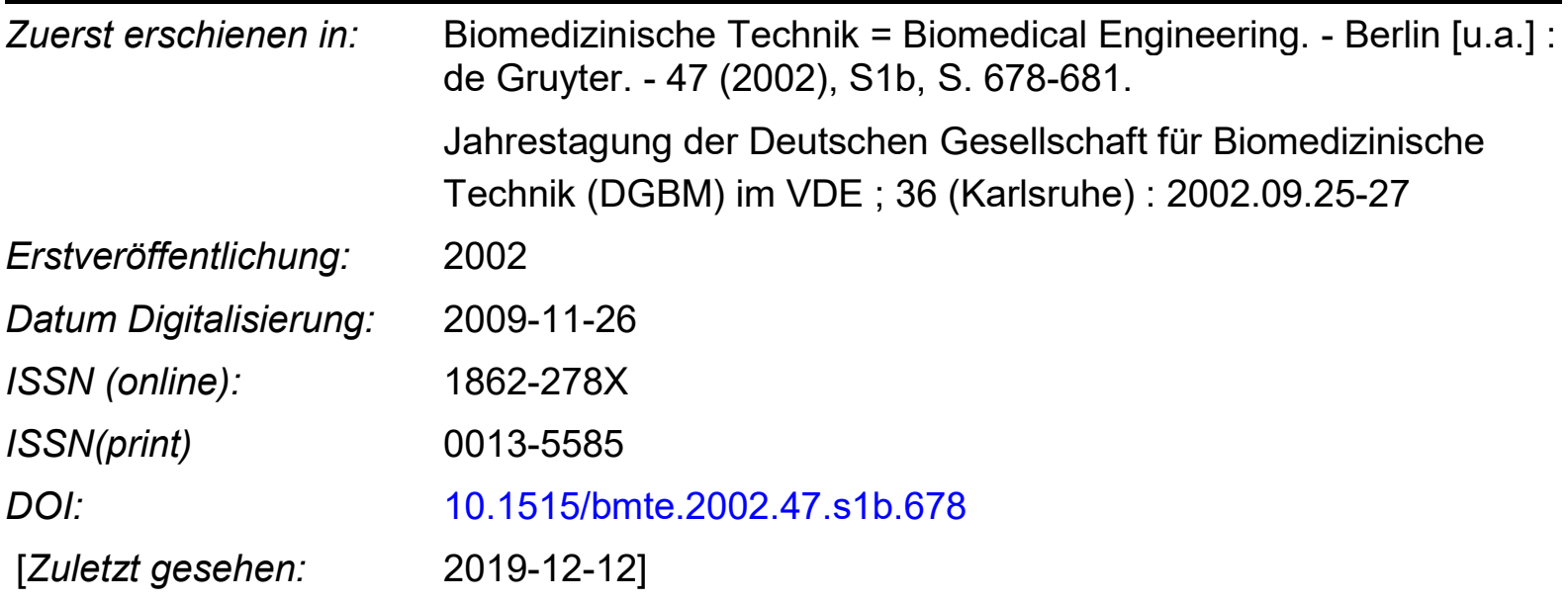

„Im Rahmen der hochschulweiten Open-Access-Strategie für die Zweitveröffentlichung identifiziert durch die Universitätsbibliothek IImenau."

"Within the academic Open Access Strategy identified for deposition by Ilmenau University Library."

„Dieser Beitrag ist mit Zustimmung des Rechteinhabers aufgrund einer (DFGgeförderten) Allianz- bzw. Nationallizenz frei zugänglich."

"This publication is with permission of the rights owner freely accessible due to an Alliance licence and a national licence (funded by the DFG, German DFG

Research Foundation) respectively." 


\title{
RETINAL VESSEL ANALYZER (RVA) - DESIGN AND FUNCTION
}

\author{
B.-U. Seifert1 ${ }^{1}$, W. Vilser ${ }^{1,2}$ \\ IMEDOS GmbH, Weimar, Germany \\ ${ }^{2}$ Technical University of Ilmenau, Ilmenau, Germany \\ b.seifert@imedos.de
}

\begin{abstract}
The Retinal Vessel Analyzer (RVA) is a measuring device for online measurement of the diameter of retinal vessels in relation to time and locations along the vessel. It is furthermore provided with several tools for analyzing the measured data. The fundamental components consist of a fundus camera with $C C D$ measuring camera attached and an advanced imageprocessing unit. The measurement range is from $90 \mu \mathrm{m}$, temporal resolution is $40 \mathrm{~ms}$ and measurement resolution is less than $1 \mu m$. Systematic error of non-linearity is $S \leq 1,6 \%$, reproducibility is given by variation coefficient: short term $v c_{s}=1,5 \%$, long term $v c_{l}=2,8 \%$.

(Supp. BMBF-13N7999)
\end{abstract}

Keywords- RVA, Retina, Microcirculation, Vessel Analysis

\section{Introduction}

In the field of retinal diagnosis there is an increasing demand for early recognition of pathological changes. One promising way is the observation of the dynamic behavior of the vessels in the retina. Vessel diameter is considered to play an important role within the auto regulative mechanisms. It is the adjusting element of the local regulation and furthermore a point of attack for pathological, age related or therapeutic changes. Diagnostic relevant information may be obtained by provocating the retinal microcirculation and measuring vessel diameter response to that provocation. A dedicated analysis of the measurement results gives an insight into different auto regulative mechanisms, which compensate for disturbances of or demands on microcirculation. Changes in auto regulative reserve could be used for early recognition.

Whereas several other research groups working in the field of image based retinal diagnostics perform single image analysis dynamic regulation processes in microcirculation only become assessable by continuous measuring methods. RVA enables the measurement of the dynamic behavior of the vessel diameter [1], therewith providing a suitable tool for several diagnostic and research applications.

An essential part of the RVA is the fundus camera (FF450, Zeiss Jena, Germany). This optical instrument enables the examination of the background area of the eye. It incorporates two optical pathways, the illumination pathway and the observation pathway. Both of them use the (dilated) pupil as an entrance to the patient's cyc. The illumination light reflected by the different layers of the retina is delivered to an observation ocular and the measuring $\mathrm{CCD}$-camera simultaneously. When passing the vessels in the background of the eye one part of light is absorbed by the red blood cells. Choosing the appropriate illumination wavelength big vessels can be easily detected in the retina's image.

\section{Materials and Methods}

RVA as a tool for retinal diagnosis and research is performing two major tasks: firstly creating the data basis of measured values and secondly the analysis of those measurements. In Fig. 1 the principle setup of the device is shown.

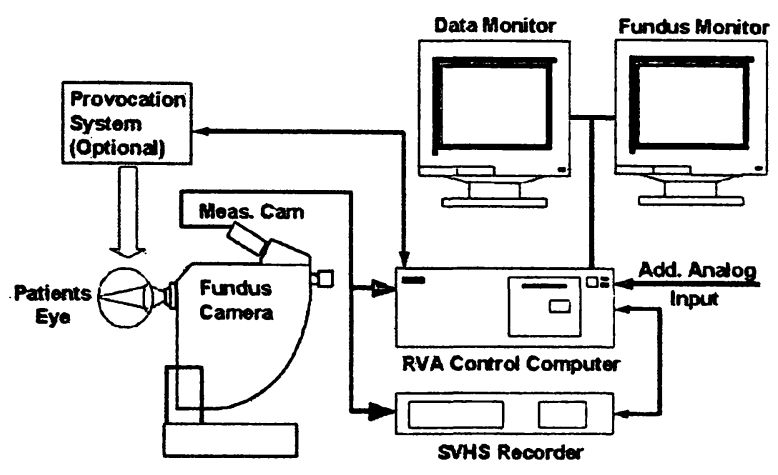

Fig. 1 RVA Principle Setup

\section{RVA - Design}

An essential part of the RVA is the fundus camera (FF450, Zeiss Jena, Germany). This optical instrument enables the examination of the background area of the eyc. It incorporates two optical pathways, the illumination pathway and the observation pathway. Both of them use the (dilated) pupil as an entrance to the patient's eye. The illumination light reflected by the different layers of the retina is imaged to the measuring CCD-camera. When passing the vessels in the background of the cyc one part of light is absorted by the red blood cells. Choosing the appropriate illumination wavelength hig ressels can to detected in the retina's image.

A CCD-measuring cam applied to the optical pathway of the fundus camera provides both the RVA contmol computer and a SVHS recorder with a standard viden signial. Video recording of a session enables subseyuent oftline measurements on the same session later on.

Two monitors come into operation. (One displays the dittis and the actual user interface. the other ane provistes a lis: view of the fundus allowing the selection off a particulat neasurement anea. The RVA computey is controllum! all connected devices and runs lle reyuirel soltwille pashages 
consisting of measurement and analysis programs, a database system and the liling solitware.

Ta achicve an optimum contrast for vessel visualization a special green filter is inserted into the illumination pathway of the fimdus ciamera. Illumination source is the common halogen bull of the camera.

As an option the system call be equipped with one of several possible provocation methods, c.g. intraocular pressure enhatncement, pure oxygen breathing or flicker light. Additional analog inputs of the RVA computer can record data from those provocational systems to track the course of provecation for analysis purposes.

\section{RVA - Measuring Principle}

To explain the measuring principle of the RVA some remarks regauding the vessel structure and the origin of the vessel image are necessary. Illumination light from the fundus camera entering the eye's pupil is reflected by the retina. The vessels on the surface of the retina are filled with blood absorbing a certain amount of the reflected light. Fig. 2 shows the vessel structure in principle.

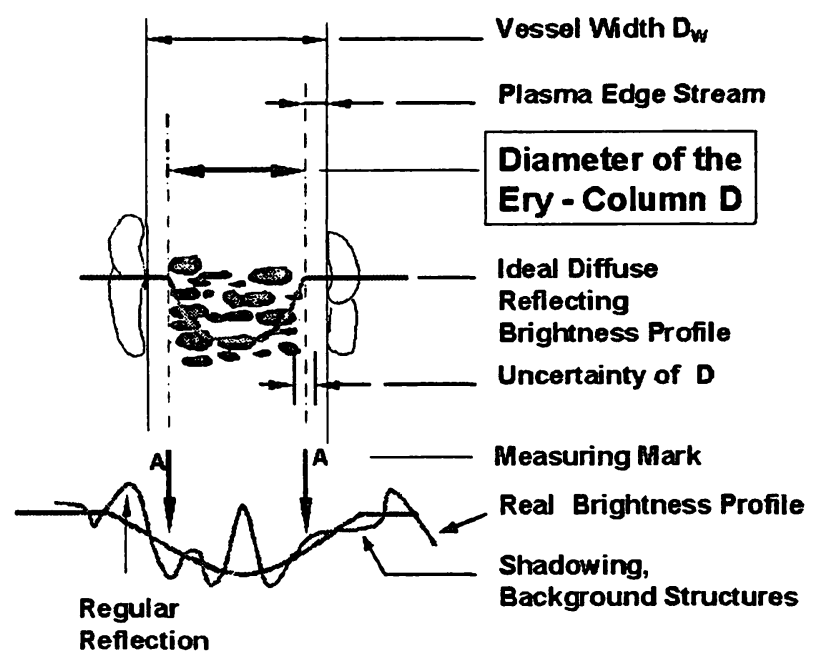

Fig. 2 Vessel Diameter Definition

Inside the vessel walls that are invisible for the fundus camera under imaging conditions, there is the column of red blood cells. It is separated from the walls by the plasma edge stream. Ideal conditions assumed a homogenous distribution of the red blood cells results into the ideal diffuse reflecting brightness profile. In reality there are several disturbances of that model e.g. shadowing structures from the background or regular reflections on the vessel surface leading to the real reflecting brightness profile. Measurement algorithms of the RVA assess vessel diameter from brightness profiles and have to compensate for disturbances. In general adaptive algorithms of the RVA perform the following tasks:

- Detection of a vessel.

- Assessment of the photometric center of gravity of the distance between the vessel edges.

- Correction of vessel sloping position.
- Monitoring of general image quality and vessel attributes to assure reasonable measurements.

$\Lambda$ Jelinition for the vessel diameter measured by the RVA can be given as: RVA measures the diameter of the column of red bloxd cells. By way of contrast the distance from wall to wall is defined as vessel width, as assessed for instance by means of fluorescence angiographies.

\section{RVA - Measuring Procedure}

Before a measurement session on the RVA can be started the fundus camera has to be properly adjusted to the patient's mydriatic eye. The life monitor should display a fundus image of good contrast without reflections. The examination method and duration is selected. To decrease the amount of acquired data the temporal resolution can be set to values higher than $40 \mathrm{~ms}$. After defining the measurement area by dragging a region of interest over a vessel on the life monitor the measurement can be started by mouse click. By means of a fixation target the patient's viewing direction should be guided in such a way that the vessels to be measured are close to the center of the live image. If the measurement area contains more than one vessel the diameter is determined for every particular vessel simultaneously. During measurement the diameter run for the selected vessels is displayed online on the data monitor.

\section{RVA - Data Basis}

Continuous recording of the vessel diameter during a measurement session results in a measuring data basis, available for further analysis after the end of the measurement. It can be displayed in a diagram like shown in Fig. 3.

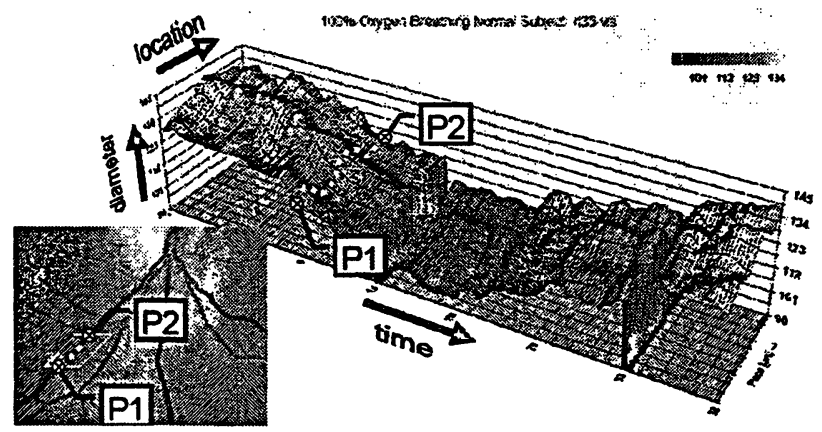

Fig. 3 RVA Data Basis (Dashed Line: Local Course Representation of Vessel Diameter)

With a temporal resolution of $40 \mathrm{~ms}$ one mean diameter value from 10 pixel columns is assessed and the location along the vessel is altered randomly. Therefore three dimensions represent the run of the vessel diameter along the vessel location as well as along the time course. As an example the dashed line in the diagram shows the mean run of the diameter inside a given time period between to points on a vessel that correspond to the points inside the measurement area on a fundus image. Displaying that part of the RVA data basis in a two dimensional diagram results in the local course view like shown in Fig. 4.

Constrictions and Dilatations on the vessel section can be detected that way. 


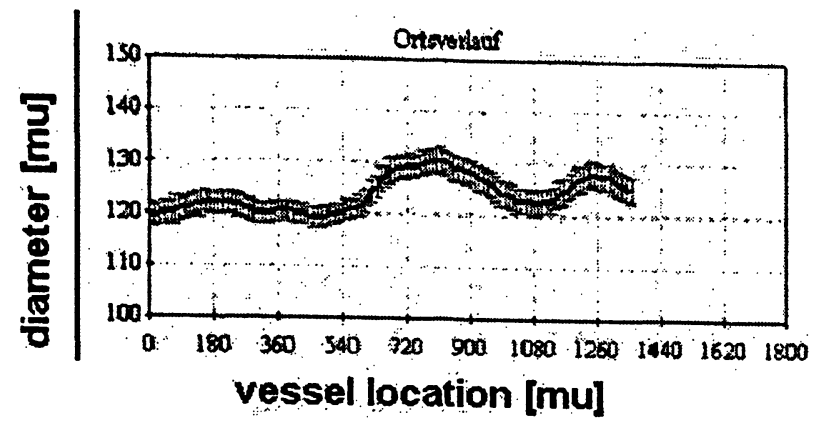

Fig. 4 Diameter Along Vessel Location

As another point of view the observation of one certain point on the vessel along the time course is shown in Fig. 5. The dashed line represents the time course of mean diameter value over a given vessel length. The examination of the temporal behavior is useful especially during provocation tests.

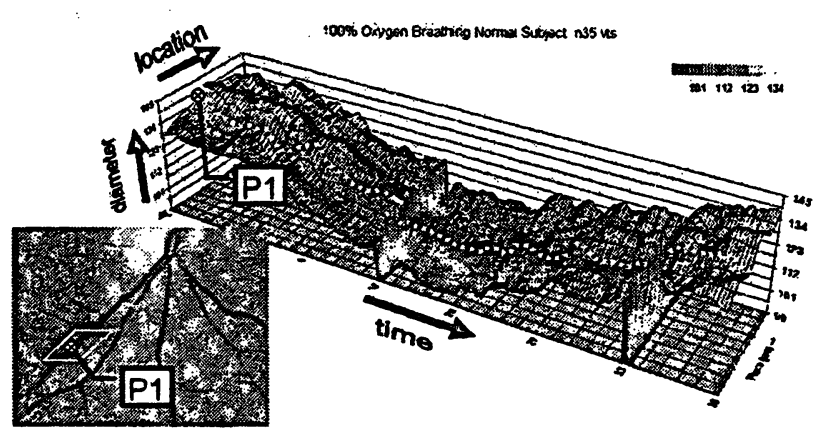

Fig. 5 RVA Data Basis (Dashed Line: Time Course Representation of Vessel Diameter)

Dropouts in vessel diameter are due to RVA measurement breaks during the session. An example of time course of mean diameter for all segments extracted from the RVA data basis can bee seen in Fig. 6

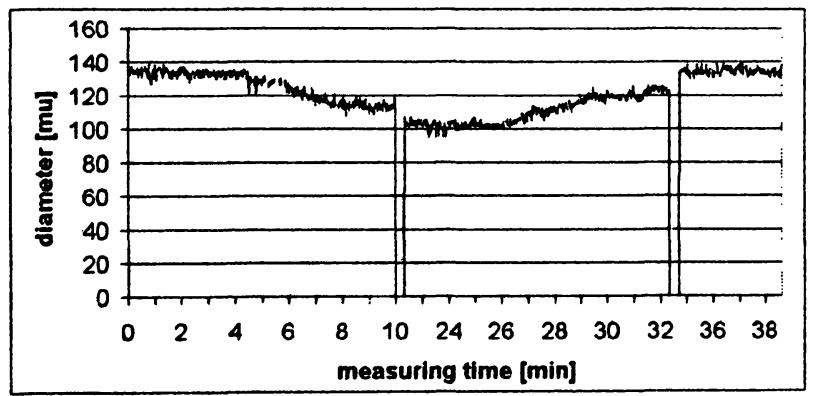

Fig. 6 Diameter along Time Course

The RVA as a measurement and analysis tool is capable of providing the following types of examination:

- Local course analysis

- Time course analysis

- Vasomotion analysis

- Functional analysis / functional imaging

This enables a wide range of applications like follow ups in ophthalmology for diagnosis and therapy, examination of effects of medicaments or basic research in microcirculation. Applications and results are described in detail in [6].

\section{Results}

To point up the potential of the RVA in the following the specifications should be given. Tab. 1 shows technical specifications of the system.

Tab. 1 Technical Specifications

\begin{tabular}{ll}
\hline Parameter & Value \\
\hline Measurement Range & $90 \mu \mathrm{m}$ \\
Measurement Resolution & $<1 \mu \mathrm{m}$ \\
Temporal Resolution & $\geq 40 \mathrm{~ms}$ \\
Image Field Angle & $30^{\circ}$ \\
Measuring Time & $\leq 10 \mathrm{~min}$ \\
Maximum Length of Vessel Segment & $3 \mathrm{~mm}$ \\
Spatial Resolution (Along Vessel & $180 \mu \mathrm{m}$ \\
Segment) & \\
Measuring Sensitivity* & $1 \mathrm{mu} / \mu \mathrm{m}$ \\
* for Gullstrand eye, accommodation to infinite
\end{tabular}

To verify the linearity of the RVA a special test target came into operation. Following European norm EN ISO 10940 the target was placed $1 \mathrm{~m}$ in front of the pupil location perpendicular to the optical pathway of the fundus camera. Illumination source was placed immediate alongside the fundus camera (ca. $10^{\circ}$ off axis of observation pathway). The target had a uniform gray background area covering the complete image area of the fundus camera. In the center an integral key was set representing a vessel phantom. Vessel edges were simulated by linear gradient of grayscale values between vessel center and target background over $1 / 3$ of diameter. Fig. 7 shows measuring results and the center part of the target image including the vessel phantom. The integration key simulates vessel diameters from 100 .. $200 \mathrm{mu}$, luminance was $\mathrm{L}=7.5$ $\mathrm{cd} / \mathrm{m}^{2}$ on target background and contrast was $\mathrm{k}=0,23$ between vessel phantom center and target background simulating usual examination conditions for retinal vessel analysis. Measurements yielded to a systematic error of non-linearity of $S \leq 1,6 \%$ (correlation coefficient $R=0,997)$. Because the accuracy of the test target $(S \leq 2 \%)$ the major part of the measured error is assumed to be caused by the target itself.

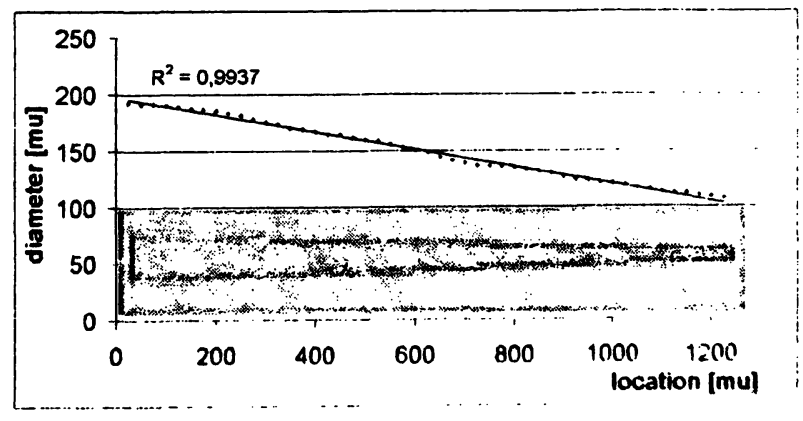

Fig. 7 Linearity Test - Target and Results

Calibration for experimental assessment of meisurng sensitivity of the RVA is performed aysun follow ing the European norm EN ISO 1(K)+4) (sctup desented in limciants

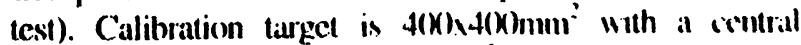

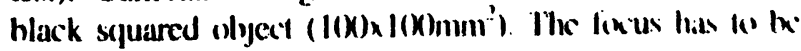


properly adjusted and an image is captured from the CCD. camera to the computer running a dedicalted calibration program. Considering the scale of the lundus eamera the calibration lactors are calculaled accorcling to the particular (CI).cimcra allached. Properly calibratced RVA outputs measuring valucs as measuring units (mu) that correspond 1:1 (1) micronkelers for the (iullstrand cye (accommodation (1) inlinite, $l=17.05(\mathrm{mmm})$.

Reprodicibility was tested by means of repeated measurements on veins. To assess short term reproducibility 12 nomal subjects were involved. Each was incasured for 5 minutes repeating the sessions after 2 hours for each subject with the same vessel location and meissuring lime. Mean vessel diameter was $160 \mathrm{mu}$ without signilicant diflerence between the sessions and variation coeflicient (short term) was $\mathrm{vc}_{\mathrm{s}}=1,5 \%$. Long lerin reproducibility ( 1 month) was assessed involving 11 nornal subjects. Mean vessel diameter was $163 \mathrm{mu}$ without signilicant difference between the sessions and variation coeflicient was $v_{1}=2,8 \%$.

\section{Discussion}

Tab. 2 [5] shows reproducibility test results for the RVA Comparison of variation coefficients of veins for short term reproducibility (s) is similar to the results presented above whereas long term reproducibility for veins (1) in [5] considerable higher. Reproducibility strongly depends on measuring conditions. Influencing factors are variation of measuring location inside image lield and on the vessel, measuring time (vasomotoric waves), eye movements in vessel direction and others.

Tab. 2 RVA Reproducibility [5]

\begin{tabular}{lll}
\hline & $\begin{array}{c}\text { Variation } \\
\text { Coefficient }\end{array}$ & $\begin{array}{c}\text { Intra class Corellation } \\
\text { Coefficient }\end{array}$ \\
\hline Arterial & $2,6 \%(\mathrm{~s})$ & $0,96(\mathrm{~s})$ \\
& $5,2 \%(\mathrm{l})$ & $0,87(\mathrm{l})$ \\
Venous & $1,3 \%(\mathrm{~s})$ & $0,98(\mathrm{~s})$ \\
& $4,4 \%(\mathrm{l})$ & $0,90(\mathrm{l})$ \\
\hline
\end{tabular}

For example optical distortion could cause errors of measuring sensitivity up to $4 \%$ if measuring location comes near the margin of the image area whereas inside $20^{\circ}$ of image area the optical distortion error is less than $1.5 \%$.

In optimal measuring conditions reproducibility can be better than the results above. Within a measuring session detection limits down to $1 \%$ of change in vessel diameter are possible.

The data basis of RVA supplies absolute values. One measuring unit corresponds exactly to one $\mu \mathrm{m}$ for the Gullstrand eye. The deviation of individual eyes to the Gullstrand eye can lead to considerable errors. By means of additional measurements of ametropia errors could be corrected in an expensive manner. Because vessel analysis is based on changes in diameter absolute values are usually not necessary. Calculation of relative values (related to baseline, local or temporal mean values) reduces the influence of optical errors considcrablc. Errors of linearity of the measuring system would causc errors of the relative values as well, therefore the cstimation of lincarity is important. The assessed non-lincarity crror represents a systematic margin of crror.

For rescarch in microcirculation the RVA provides a measuring device and numcrous analysis methods to observe retinal microcirculation offering a wide range of possible applications. Results show that permanent monitoring of proper examination conditions assumed RVA is a suitable tool for retinal vessel analysis.

\section{Acknowledgements}

OIT-OpththalmoInnovation Thüringen, Supp. by BMBF13 N7999

\section{References}

[1] W. Vilser, Th. Riemer, Ch. Bräuer-Burchardt, K. Münch, I. Senff, W. Kleen, K. Bachmann, S. Pietscher, G. E. Lang, G. K. Lang, "Retinal Vessel Analyzer (RVA) a new measuring system for examination of local and temporal vessel behavior", [ARVO-Abstract] Invest Ophthalmol Vis Sci., vol.38(4), S1050 Abstract nr 4897, 1997

[2] A. Hoover, V. Kouznetsova, M. Goldbaum, „Locating Blood Vessels in Retinal Images by Piecewise Threshold Probing of a Matched Filter Response“, IEEE Transactions on Medical Imaging, vol.19, No.3, pp. 203-210, March 2000

[3] D. Usher, M. Himaga, E. Mensah, T.H. Williamson, J.F. Boyce, J. Marshall,'The automated diagnosis of diabetic retinopathy", IOVS, vol. 42, No.4, pp. S807, 2001.

[4] B. Sander, J. Godt, H. Lund-Andersen, M. Grunkin, D. Owens, N. Larsen, M. Larsen, „Automated detection of fundus photographic dark lesions in diabetic retinopathy", IOVS, vol. 42, No. 4, pp. S809, 2001.

[5] K.Polak, G. Dorner, B. Kiss, E. Polska, O. Findl, G. Rainer, H.-G. Eichler, L. Schmetterer, ,Evaluation of the Zeiss retinal vessel analyser", Br J Ophthalmol; 84, pp. 1285-1290, 2000

[6] W. Vilser, E. Nagel, I. Lanzl, „Retinal Vessel Analysis - New Possibilities“, Biomed Tech, vol. 47, Suppl. 1, 2002 